\title{
An Electronic Data Capture Framework (ConnEDCt) for Global and Public Health Research: Design and Implementation
}

Caleb J Ruth ${ }^{1 *}$, BS; Samantha Lee Huey ${ }^{2 *}$, BS, PhD; Jesse T Krisher ${ }^{2}$, BS, CPH; Amy Fothergill², MPH; Bryan M Gannon $^{2,3}$, PhD; Camille Elyse Jones ${ }^{2}$, MPH; Elizabeth Centeno-Tablante ${ }^{2}$, MS; Laura S Hackl ${ }^{2}$, PhD; Susannah Colt $^{2}$, PgDip, PhD; Julia Leigh Finkelstein ${ }^{2,3}$, MPH, ScD; Saurabh Mehta ${ }^{2,3}$, MBBS, ScD

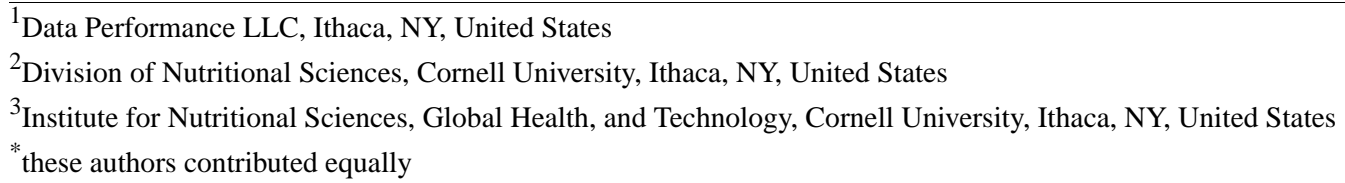

\section{Corresponding Author:}

Saurabh Mehta, MBBS, ScD

Division of Nutritional Sciences

Cornell University

314 Savage Hall

Ithaca, NY

United States

Phone: 1 (607) 2552640

Email: $\underline{\text { smehta@cornell.edu }}$

\begin{abstract}
Background: When we were unable to identify an electronic data capture (EDC) package that supported our requirements for clinical research in resource-limited regions, we set out to build our own reusable EDC framework. We needed to capture data when offline, synchronize data on demand, and enforce strict eligibility requirements and complex longitudinal protocols. Based on previous experience, the geographical areas in which we conduct our research often have unreliable, slow internet access that would make web-based EDC platforms impractical. We were unwilling to fall back on paper-based data capture as we wanted other benefits of EDC. Therefore, we decided to build our own reusable software platform. In this paper, we describe our customizable EDC framework and highlight how we have used it in our ongoing surveillance programs, clinic-based cross-sectional studies, and randomized controlled trials (RCTs) in various settings in India and Ecuador.
\end{abstract}

Objective: This paper describes the creation of a mobile framework to support complex clinical research protocols in a variety of settings including clinical, surveillance, and RCTs.

Methods: We developed ConnEDCt, a mobile EDC framework for iOS devices and personal computers, using Claris FileMaker software for electronic data capture and data storage.

Results: ConnEDCt was tested in the field in our clinical, surveillance, and clinical trial research contexts in India and Ecuador and continuously refined for ease of use and optimization, including specific user roles; simultaneous synchronization across multiple locations; complex randomization schemes and informed consent processes; and collecting diverse types of data (laboratory, growth measurements, sociodemographic, health history, dietary recall and feeding practices, environmental exposures, and biological specimen collection).

Conclusions: ConnEDCt is customizable, with regulatory-compliant security, data synchronization, and other useful features for data collection in a variety of settings and study designs. Furthermore, ConnEDCt is user friendly and lowers the risks for errors in data entry because of real time error checking and protocol enforcement.

(J Med Internet Res 2020;22(8):e18580) doi: 10.2196/18580

\section{KEYWORDS}

data science; data collection; database management systems; global health; public health; data management; health information management; population surveillance; longitudinal studies; randomized controlled trial; Electronic Data Capture (EDC) 


\section{Introduction}

\section{Background}

Our research on human nutrition and global health spans multiple countries, encompasses both interventional and observational study designs, and requires secure data collection and management. Noting the benefits of electronic data capture (EDC) over paper-based data capture [1,2], beginning in 2012, we searched for an EDC tool for our research projects on human health and were unable to find a package that met our needs. With several research projects on our roadmap that would be deployed in remote, international regions with complex longitudinal protocols, strict eligibility requirements, and distributed research teams, we aimed to use EDC over paper-based data capture to enforce our study protocols and provide better data security, data validation, and have instant access to data. In surveying EDC packages currently available on the market (Table 1), some had to be ruled out completely because of the unreliable internet coverage in areas we focused on for our studies (compared with Research Electronic Data Capture [REDCap], which had not yet released its mobile app when our initial research projects were being conducted in 2013
[3]). Other packages identified did not provide the required features specific to our study protocols, such as our strict data security specifications (compared with Open Data Kit [ODK]) [4]. To address this, we felt that we had the correct clinical and technical team in place to build our own EDC tools to solve our needs and potentially those of a large community of researchers in the future.

\section{Objectives}

As we developed our plans for creating the EDC tools for our research studies, we decided that instead of a custom tool for each study, a better investment would be one reusable platform that could be applied to each research project, with limited customizations for each iteration. The upfront investment would be higher, but subsequent deployments should build on the initial investment. Mobile phones and tablet devices are commonly used, even in lower-resource settings where our studies are located. We felt that an EDC tool for tablets would be easier for our local research staff to learn, more transportable, and less expensive to deploy than laptops. In this paper, we describe ConnEDCt, the EDC platform that we developed and successfully deployed for clinic-based cross-sectional studies, randomized controlled trials (RCTs), and surveillance projects. 
Table 1. ConnEDCt, REDCap, and Open Data Kit electronic data capture systems.

\begin{tabular}{|c|c|c|c|c|}
\hline Feature & ConnEDCt & REDCap $^{\mathrm{a}}$ & REDCap Cloud & $\begin{array}{l}\text { Open Data Kit } 1 \text { Suite, } \\
\text { ODK- } X^{\mathrm{b}} \text { Suite }\end{array}$ \\
\hline Requirement to use & FileMaker license & $\begin{array}{l}\text { Nonprofit organization with suf- } \\
\text { ficient } \text { IT }^{\mathrm{c}} \text { infrastructure. Join } \\
\text { REDCap Consortium, license } \\
\text { agreement with Vanderbilt Uni- } \\
\text { versity. Must submit new license } \\
\text { to obtain a new REDCap system } \\
\text { per each group of users }\end{array}$ & $\begin{array}{l}\text { Fee-based hosting by a } \\
\text { third-party company }\end{array}$ & $\begin{array}{l}\text { Web access, user comfort in } \\
\text { coding }\end{array}$ \\
\hline Mobile app and platform & $\begin{array}{l}\text { FileMaker Go on iPhone, } \\
\text { iPad }\end{array}$ & $\begin{array}{l}\text { REDCap mobile app; MyCap on } \\
\text { iPhone, iPad, Android }\end{array}$ & $\begin{array}{l}\text { REDCap Cloud mobile } \\
\text { app on iPhone, iPad, An- } \\
\text { droid }\end{array}$ & $\begin{array}{l}\text { Yes: ODK Connect, An- } \\
\text { droid app }\end{array}$ \\
\hline $\begin{array}{l}\text { Software and operating sys- } \\
\text { tem }\end{array}$ & $\begin{array}{l}\text { Claris FileMaker on Mac, } \\
\text { Windows }\end{array}$ & $\begin{array}{l}\text { Web server, database server, } \\
\text { SMTP }^{\mathrm{d}} \text { email server, file server } \\
\text { (optional) on any laptop }\end{array}$ & $\begin{array}{l}\text { Web server, database } \\
\text { server, SMTP email } \\
\text { server, fileserver (option- } \\
\text { al) on any laptop }\end{array}$ & $\begin{array}{l}\text { ODK Aggregate app, ODK } \\
\text { Briefcase app, ODK Central } \\
\text { app; XML documents creat- } \\
\text { ed using ODK JavaRosa li- } \\
\text { brary/any laptop }\end{array}$ \\
\hline Web based & Yes & Yes & Yes & Yes \\
\hline Offline data capture & Yes & Yes & Yes & Yes \\
\hline $\begin{array}{l}\text { Data synchronization: soft- } \\
\text { ware }\end{array}$ & Yes: MirrorSync [5] & Yes & Yes & Yes \\
\hline Study designs & Customizable & Customizable & Customizable & Customizable \\
\hline $\begin{array}{l}\text { Study protocol enforcement } \\
\text { for scheduled and unsched- } \\
\text { uled encounters }\end{array}$ & Yes & Not noted & Not noted & Not noted \\
\hline Electronic-informed consent & Yes & Yes & Yes & Yes \\
\hline $\begin{array}{l}\text { Automated eligibility deter- } \\
\text { mination }\end{array}$ & Yes & Not noted & Not noted & Yes \\
\hline Randomization & $\begin{array}{l}\text { Yes: any form can be im- } \\
\text { plemented }\end{array}$ & $\begin{array}{l}\text { Yes: any form can be implement- } \\
\text { ed }\end{array}$ & $\begin{array}{l}\text { Yes: any form can be im- } \\
\text { plemented }\end{array}$ & $\begin{array}{l}\text { Yes: predetermined types } \\
\text { allowed }\end{array}$ \\
\hline $\begin{array}{l}\text { Conditional } \mathrm{CRFs}^{\mathrm{e}} \text { based on } \\
\text { midline serial sampling or } \\
\text { other criteria }\end{array}$ & Yes & Not noted & Not noted & Not noted \\
\hline Open source & No & No & No & Yes \\
\hline $\begin{array}{l}\text { Regulatory-compliant secu- } \\
\text { rity and encryption }\end{array}$ & $\begin{array}{l}\text { Title } 21 \mathrm{CFR}^{\mathrm{f}} \text { Part } 11, \\
\text { HIPAA }^{\mathrm{g}}, \mathrm{GDPR}^{\mathrm{h}}\end{array}$ & $\begin{array}{l}\text { HIPAA, Part 11, FISMA }{ }^{\mathrm{i}} \text { stan- } \\
\text { dards (low, medium, or high), } \\
\text { GDPR, depending on environ- } \\
\text { ment }\end{array}$ & $\begin{array}{l}\text { Best practice security, } \\
\text { Title } 21 \text { CFR Part } 11 \\
\text { compliant, industry regu- } \\
\text { lations, HIPAA compli- } \\
\text { ant, data privacy technol- } \\
\text { ogy }\end{array}$ & $\begin{array}{l}\text { Security of third-party li- } \\
\text { braries are not vetted, re- } \\
\text { quire user's security staff to } \\
\text { review libraries and source } \\
\text { code on GitHub }\end{array}$ \\
\hline Secure data collection & Yes & Yes & Yes & $\begin{array}{l}\text { Encrypted form security; } \\
\text { only transmissions over a } \\
\text { secure HTTPS }{ }^{j} \text { connection } \\
\text { are obscured from observers } \\
\text { and prevent tampering in } \\
\text { transmission }\end{array}$ \\
\hline Export type & $\begin{array}{l}\text { Excel, can be customized } \\
\text { per user requirement }\end{array}$ & $\begin{array}{l}\text { Excel, PDF, SPSS, SAS, Stata, } \\
\text { R }\end{array}$ & $\begin{array}{l}\text { Excel, PDF, SPSS, SAS, } \\
\text { Stata, R }\end{array}$ & $\begin{array}{l}\text { Export to } \mathrm{CSV}^{\mathrm{k}}, \mathrm{JSON}^{\mathrm{l}} \text { (text } \\
\text { only), } \mathrm{KML}^{\mathrm{m}} \text { (for mapping } \\
\text { applications) }\end{array}$ \\
\hline $\begin{array}{l}\text { Logic checks/concurrent er- } \\
\text { ror checking }\end{array}$ & Yes & Yes & Yes & Yes \\
\hline Customizable user roles & Yes & Yes & Yes & Yes \\
\hline $\begin{array}{l}\text { Translation and cultural } \\
\text { adaptation }\end{array}$ & Yes & Yes & Yes & Yes \\
\hline
\end{tabular}




\begin{tabular}{|c|c|c|c|c|}
\hline Feature & ConnEDCt & REDCap $^{\mathrm{a}}$ & REDCap Cloud & $\begin{array}{l}\text { Open Data Kit } 1 \text { Suite, } \\
\text { ODK- } \mathrm{X}^{\mathrm{b}} \text { Suite }\end{array}$ \\
\hline Signature capture & Yes & Yes & Yes & Yes \\
\hline Ease of form construction & $\begin{array}{l}\text { Create using FileMaker } \\
\text { software on laptop inter- } \\
\text { face; use Excel to record } \\
\text { variable lists; methods } \\
\text { adaptable per user's com- } \\
\text { fort level }\end{array}$ & $\begin{array}{l}\text { Web-based designer, offline data } \\
\text { dictionary file on Microsoft } \\
\text { Word, Excel }\end{array}$ & $\begin{array}{l}\text { Web-based designer, of- } \\
\text { fline data dictionary file } \\
\text { on Microsoft Word, Ex- } \\
\text { cel }\end{array}$ & $\begin{array}{l}\text { Excel-based form creation } \\
\text { (XLSForm), drag-and-drop } \\
\text { form creation (ODK Build) }\end{array}$ \\
\hline Customizable & Yes & Yes & Yes & Yes \\
\hline Audit trail & Yes & Yes & Yes & Yes \\
\hline
\end{tabular}

${ }^{\mathrm{a}}$ REDCap: Research Electronic Data Capture.

${ }^{\mathrm{b}}$ ODK-X: Open Data Kit-X (formerly known as ODK-2).

${ }^{\mathrm{c}}$ IT: information technology.

${ }^{\mathrm{d}}$ SMTP: simple mail transfer protocol.

${ }^{\mathrm{e}} \mathrm{CRF}$ : case report form.

${ }^{f}$ CFR: Code of Federal Regulations.

${ }^{\mathrm{g}}$ HIPAA: Health Insurance Portability and Accountability Act.

${ }^{\mathrm{h}}$ GDPR: General Data Protection Regulation.

${ }^{\mathrm{i}}$ FISMA: Federal Information Security Management Act.

${ }^{j}$ HTTPS: hypertext transfer protocol secure.

${ }^{\mathrm{k}} \mathrm{CSV}$ : comma-separated value.

${ }^{1}$ JSON: Javascript Object Notation.

${ }^{\mathrm{m}} \mathrm{KML}$ : keyhole markup language.

\section{Methods}

\section{Technical Details}

ConnEDCt consists of a distributed database, data entry interfaces, data management interfaces, scripted business rules, data synchronization, and data security features [6]. The main components of ConnEDCt are a client-side database, a cloud-based database server, a data synchronization engine, iOS mobile devices, and laptop personal computers. ConnEDCt is built with FileMaker Pro Advanced by Claris International Inc. [7], a commercial, cross-platform, relational database platform. FileMaker Pro Advanced provided the important advantages of rapid development and the ability to deploy cross-platform on iOS, Mac, and Windows platforms. One tool is therefore easily deployed on iPads and laptops, which are our primary computing devices. ConnEDCt's features, quality, and safety are reliable compared with existing guidelines and requirements, including Good Clinical Data Management Practices [8], the Food and Drug Administration (FDA) [9], and Title 21 Code of Federal Regulations (CFR) Part 21 [10].

\section{Configuration of ConnEDCt}

Study designers conduct a design process using Microsoft Excel templates to define the study schema. A forms schedule template is used to define case report form (CRF) usage over scheduled visits in a longitudinal study. The intersection of CRFs and scheduled visits in a two-dimensional matrix in this template shows which CRFs are instantiated per visit. In addition, CRFs can be defined for unscheduled instantiation. Study designers use data dictionary Excel templates to define variables within CRFs along with select lists, skip logic, etc. The study designers then document the eligibility criteria formulas within another Excel template.

The data dictionaries are then translated into FileMaker tables and fields in a FileMaker template file. FileMaker provides an easy-to-use interface for creating CRF tables and fields within the integrated development environment. A study designer can accomplish this step with minimal training. The final steps of implementation require some developer skills and are easily repeatable within a framework structure. These implementations include the forms schedule schema, eligibility criteria formulas, CRF validation, loading a randomization table, and synchronization. Once ConnEDCt has been configured for a study, the server files are then hosted on an internet-connected server, and client files are deployed to laptops and iPads.

We continue to develop the features of ConnEDCt further to enable study designers to complete the implementation of the majority of study protocols with minimal developer involvement. We anticipate that to maximize the flexibility of study protocols, we will always benefit from some custom or specialized development for novel EDC features.

\section{Key Features}

\section{Management of Research Teams and Different Roles}

Several roles were required to implement and operate ConnEDCt. Software developers and systems integrators performed programming and other technical tasks such as database and server management. Data managers helped translate clinical requirements into data definitions and used software interfaces to define the scheduled and unscheduled study events, CRFs, variables, validation criteria, and eligibility 
criteria. Each study event involves capturing data in one or more CRFs. A CRF is a collection of related variables to be entered during a study event. The data manager also manages data exports for analysis by using external statistical and analytics software. Research associates/assistants perform data entry during interviews, direct observations, and also enter laboratory results. User-level privileges to various database features and data vary by role. For example, research assistants may create new participants and enter data, whereas research coordinators and principal investigators may additionally edit the entered data in the event of errors found as data managers. Different users can access ConnEDCt with their own account, secured by a custom username and password, which contains different levels of privileges depending on the user role.

\section{Asynchronous Data Synchronization}

A key feature of ConnEDCt is the ability to capture data on a mobile device while offline and, at a later time, when an internet connection is available, send the captured data to a cloud-based server. In addition, study schema revisions can be deployed on mobile devices. The asynchronous data transport can be finely controlled such that data can be selectively deployed to individual mobile devices. In this manner, data can be synchronized in 1 direction only to minimize data traffic and to maintain data privacy. Data previously stored in mobile devices will remain in the FileMaker Go app on mobile devices to enable research assistants to track participant progress throughout the study. After study completion, the data are completely removed from mobile devices.

\section{Real-Time Assessment of Eligibility}

Assessing eligibility is a key process in participant screening and study enrollment. ConnEDCt provides automated features to determine participant eligibility based on criteria specified a priori. Eligibility algorithms are evaluated programmatically at runtime to provide feedback on participant eligibility. Figure 1 shows the workflow for evaluating the eligibility of a new participant. As eligibility criteria may be defined by including variables from different CRFs, eligibility is evaluated on completion of each predicate CRF. Participant exclusion can be determined based on a negative evaluation of a single criterion, whereas inclusion is determined on completion of all predicate CRFs. 
Figure 1. Eligibility protocol for (A) clinical setting: FeverPhone, Ecuador; (B) RCT, Mumbai; (C) RCT, South India; (D) surveillance study, South India. RCT: randomized controlled trial.
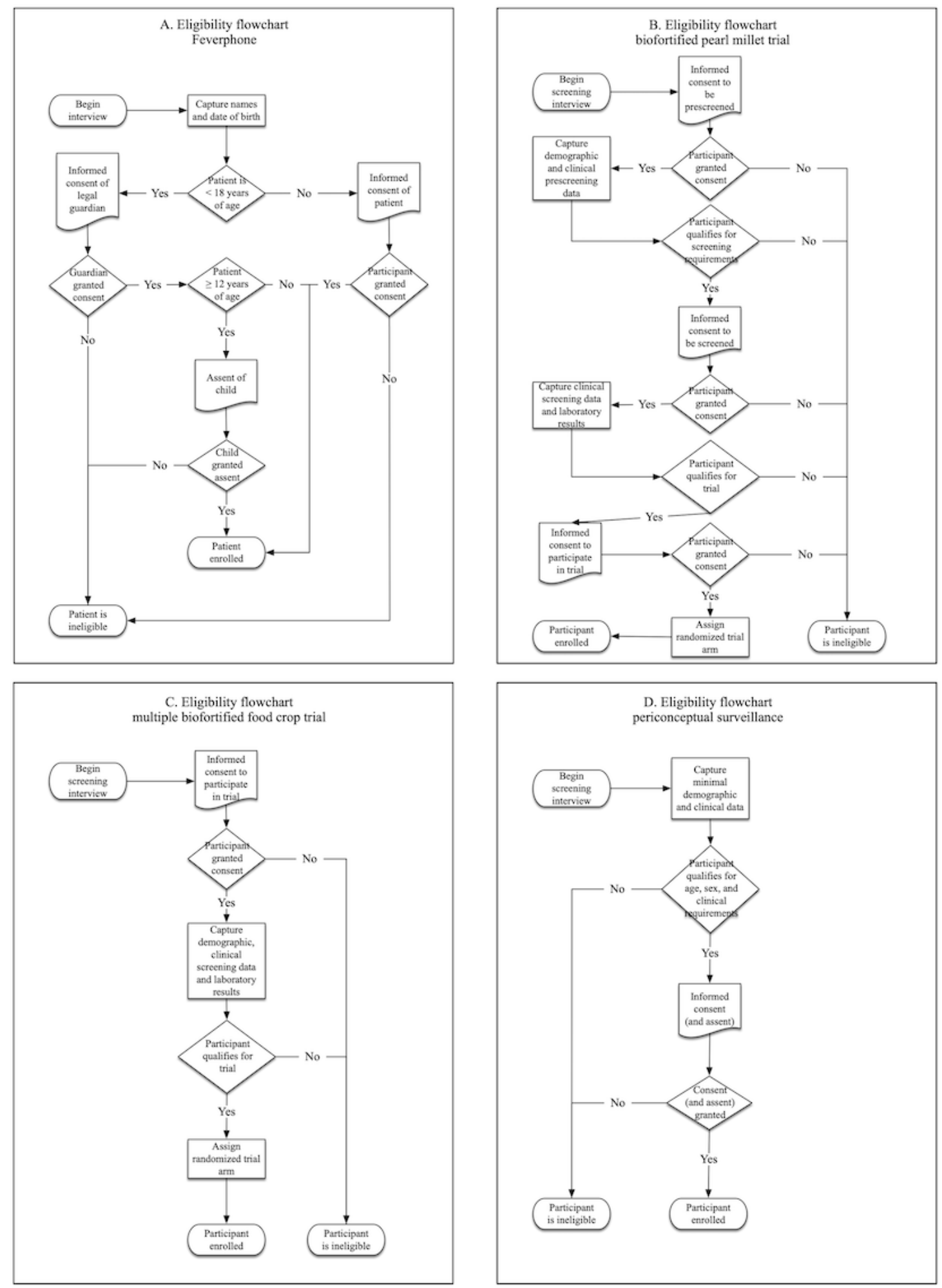

\section{Electronic Consent and Signatures}

Electronic signatures and health records are regulated under the FDA Title 21 CFR Part 11 of the CFRof the United States [11]. Part 11 requires strict data security, including user authentication, encryption, and auditability. Data security regulations vary by country, and ConnEDCt is compliant with currently known rules and adaptable to potential future data

security requirements. For example, when study protocols require audiovisual evidence of consent, ConnEDCt can use a mobile device's built-in camera and microphone to capture the consent process.

\section{Enforcement of Complex Study Protocols}

We designed ConnEDCt to support complex, longitudinal study protocols and minimize training requirements for field research 
staff. ConnEDCt provides features to support predefined longitudinal study schema, automated assignment of randomized study arms and midline serial sampling, and automated scheduling of additional CRFs based on captured responses. When ConnEDCt is configured for a study, visit records (eg, screening, baseline, midline, and endline) will be created as dictated by the study schema. CRFs are organized within appropriate visits. A visit is complete when all CRFs within the visit have been completed and signed. The interface clearly shows the schedule of visits (Figure 2) and the required CRFs for a particular visit (Figure 3). When the study includes an RCT, ConnEDCt can reference a randomization table to automatically assign a randomized arm to an eligible participant. When the study protocol includes midline serial sampling, ConnEDCt uses the internal randomization table to selectively include designated CRFs at the randomly designated midline visit (Figure 4). When responses to study questions determine the need for additional CRFs, they will be created on demand and presented in the visit schedule-for example, a response to a question on the number of pregnancies may trigger the same number of pregnancy CRFs, or a response on a sick form may trigger a blood or saliva sample CRF. These features reduce the learning curve for the research team. We believe that this improves the interview experience by allowing research assistants to focus on the study participant instead of on data management and study protocol compliance.

\section{Designed for Flexibility and Reuse}

The ConnEDCt architecture has a flexible schema and is designed to be adaptable to varying study protocols. Therefore, ConnEDCt is designed for flexibility and reuse. Events, event types, event forms, form schedules, form types, and eligibility criteria are defined in the data model and can be modified in the user interface. Validation rules and postprocessing triggers are built in a framework, minimizing the amount of custom code. In this manner, subsequent research studies can be implemented with minimal modification to the conceptual schema or programmatic code. When a new study protocol is implemented, entities for visits and CRFs are created, whereas the programming that controls participant management, navigation, eligibility, and study protocols responds to changes in study protocol design.

\section{Language Customization and Data Location}

The ConnEDCt system can also accommodate CRFs in multiple languages, as shown in Figure 5. Professionally translated questionnaires can be entered into FileMaker using native multilingual keyboards. Furthermore, data can be synchronized to and primarily stored on in-country servers, where available, to comply with local laws in many settings. 
Figure 2. Schedule of visits for (A) clinical setting: FeverPhone, Ecuador; (B) RCT, Mumbai; (C) RCT, South India; (D) surveillance, South India. RCT: randomized controlled trial.
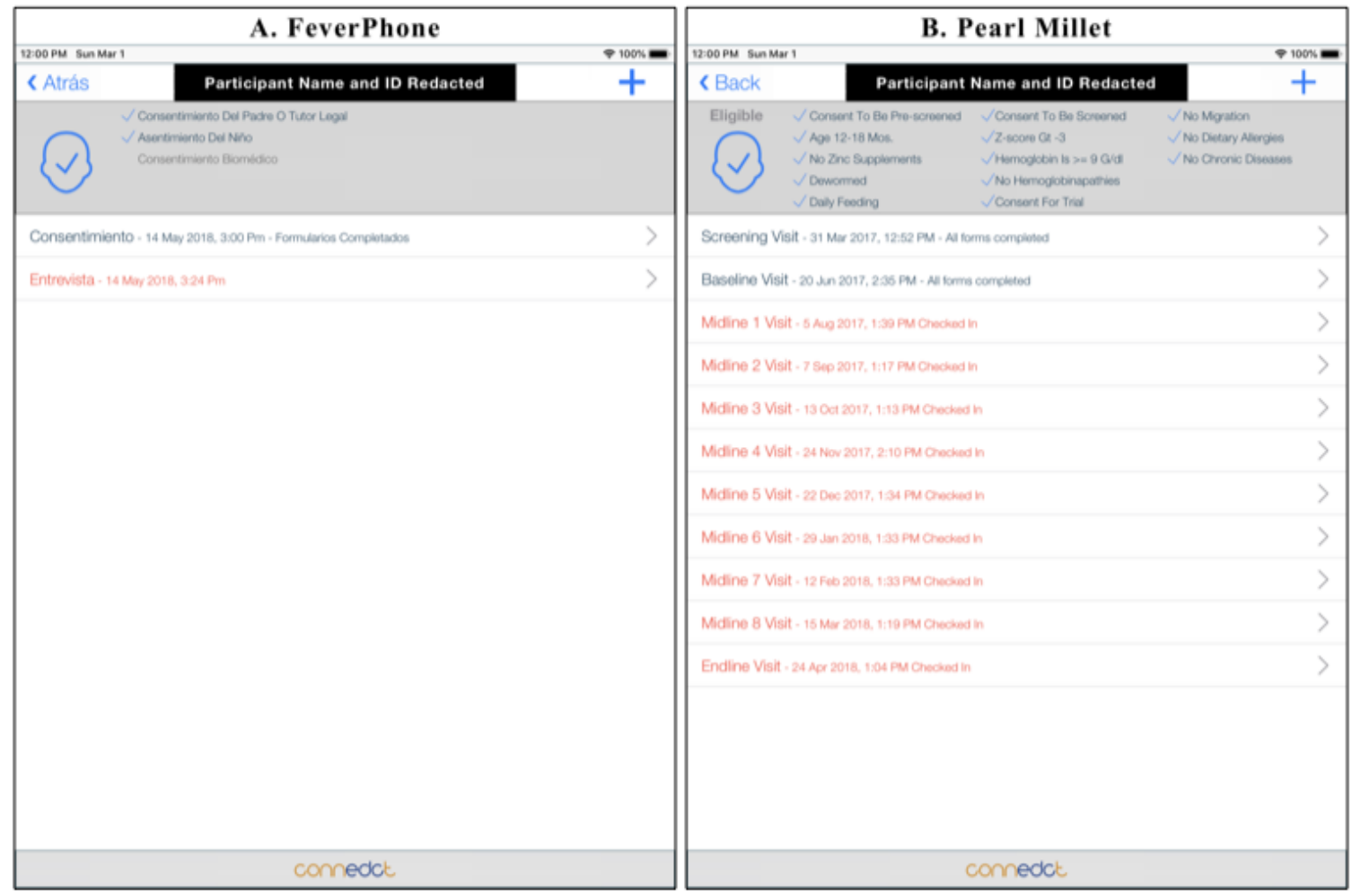

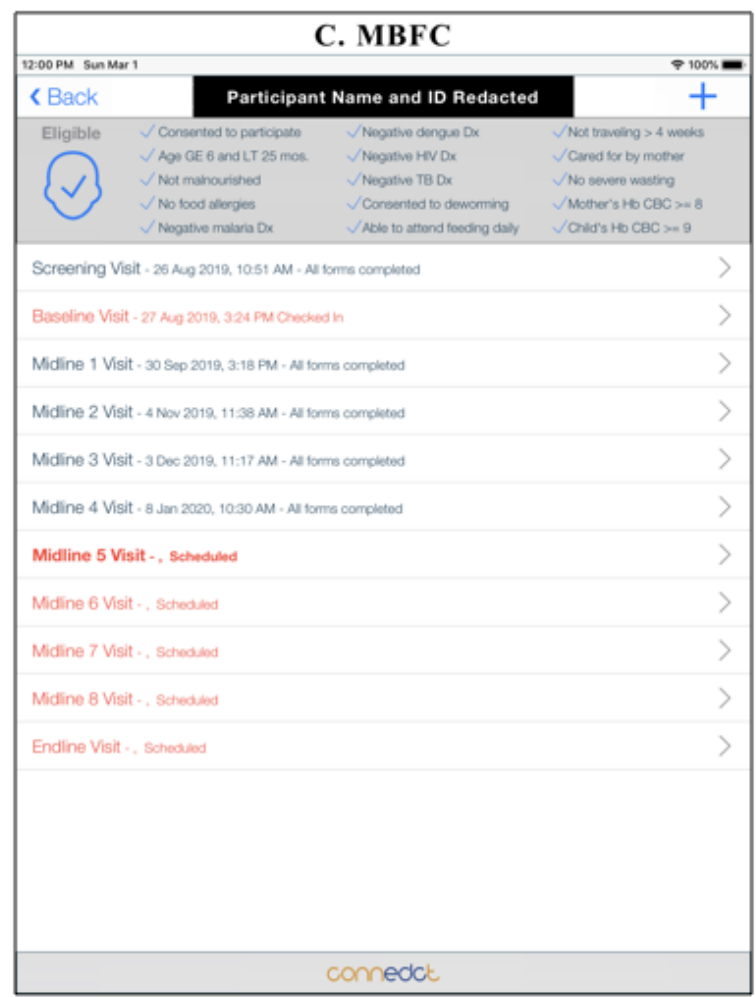

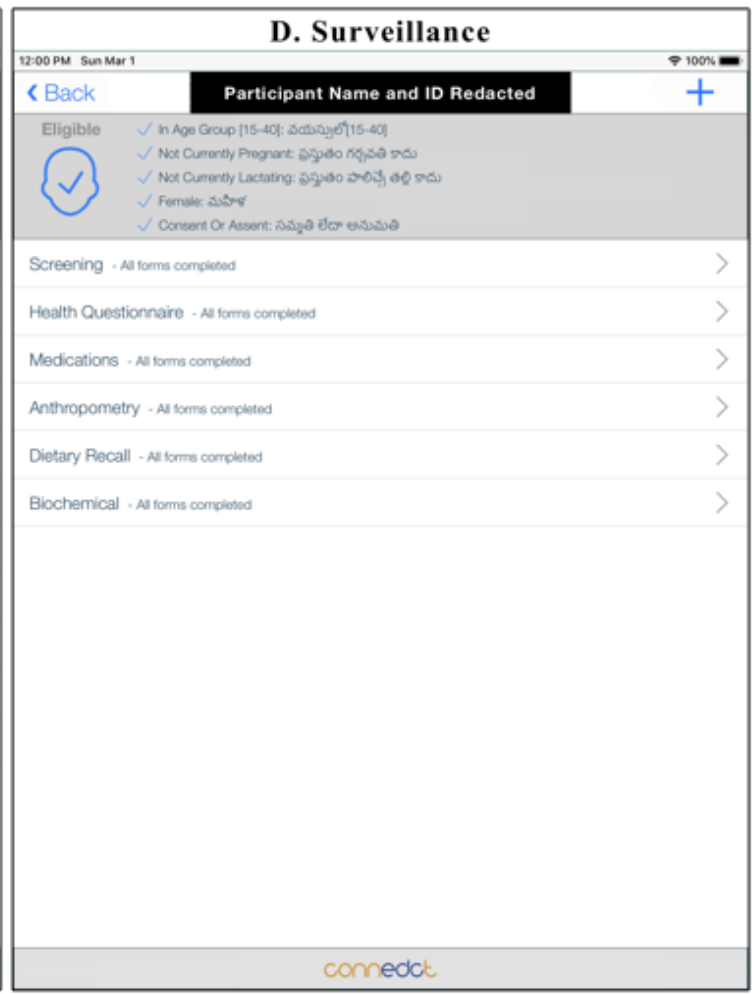


Figure 3. Schedule of visits for (A) clinical setting: FeverPhone, Ecuador; (B) RCT, Mumbai; (C) RCT, South India; (D) surveillance study, South India. RCT: randomized controlled trial.

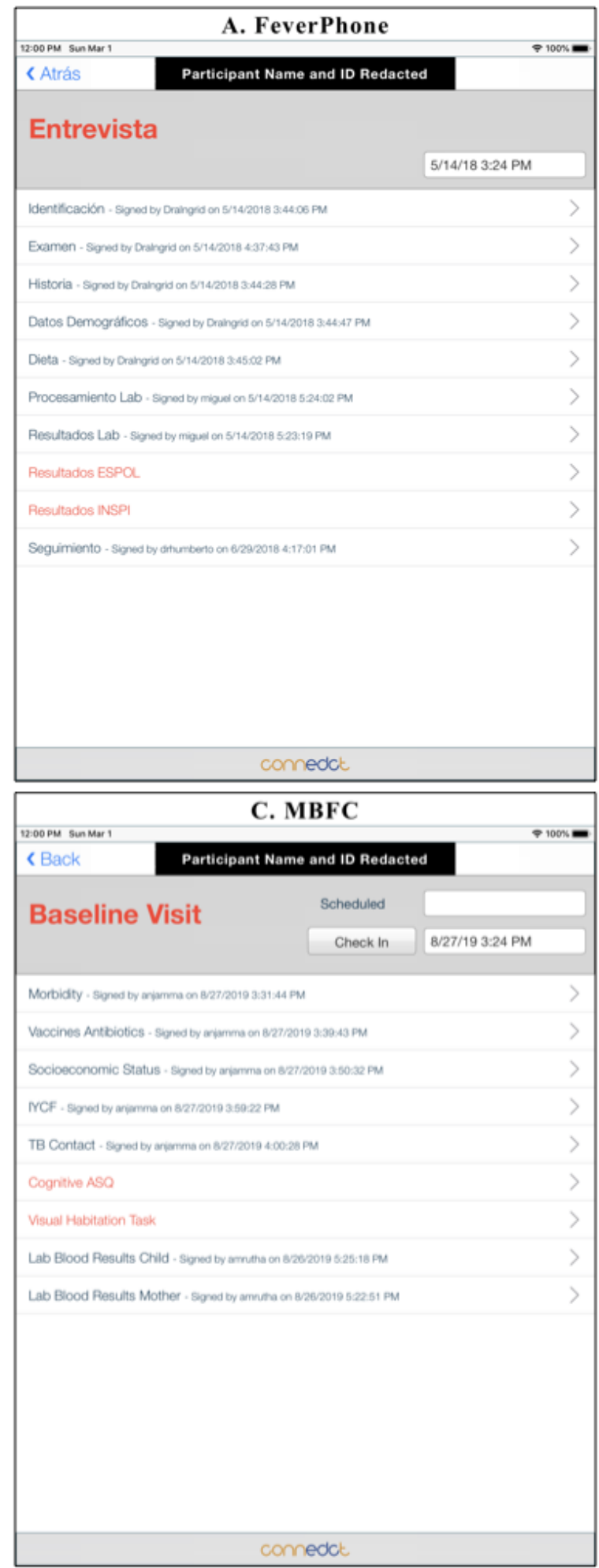
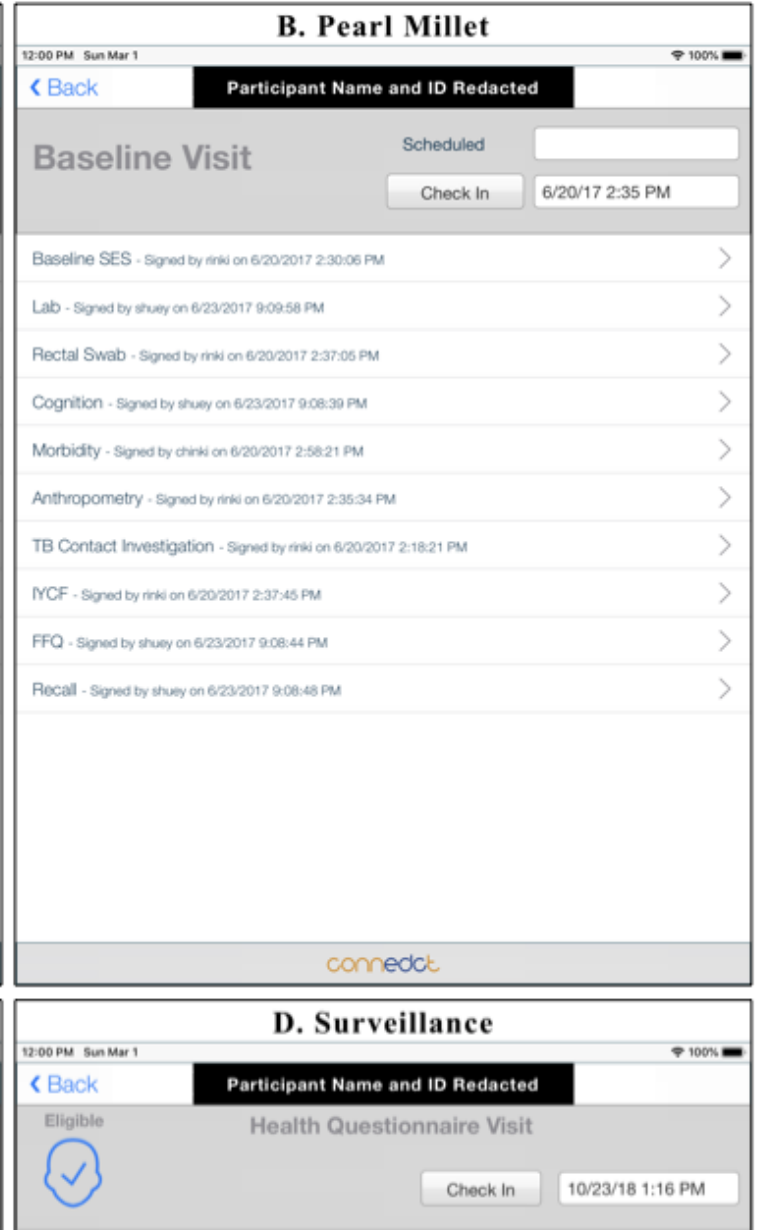

Demographics - Signed by Nagamaba on 10232018 124:37 PM

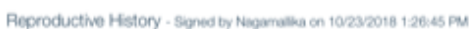

Pregnancy - Siged by Nogammba on 10232018 1:30.07 PN

Pregnancy - Signed by Nogumuba on 10232018 1:37:15 PM

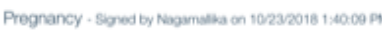

Environmental Exposure - Sonod by Nopanaba on 10232018 1:43:35 PM

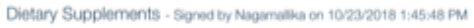

Fever and Heat Exposure - Sprod by Nagarmallis on 10232018 1:46:38 PM 
Figure 4. Example of display of all CRFs required for (A) baseline visit, for clinical setting: FeverPhone, Ecuador; (B) baseline visit for RCT, South India; and (C) health questionnaire visit for surveillance, South India. CRF: case report form; RCT: randomized controlled trial.

\section{Pearl Millet}

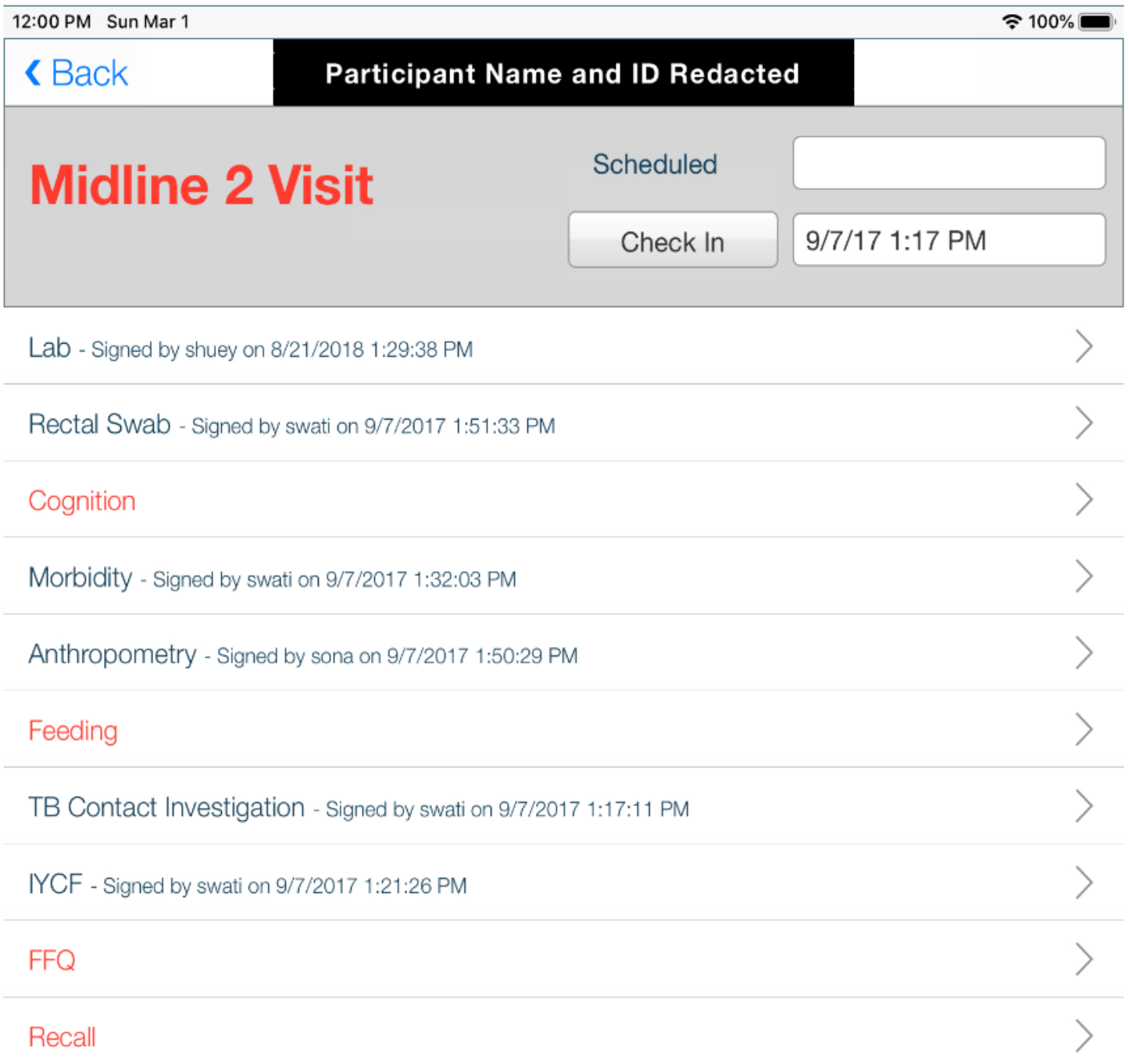


Figure 5. CRF shown in the local language, Telugu, for RCT, South India. CRF: case report form; RCT: randomized controlled trial.

MBFC

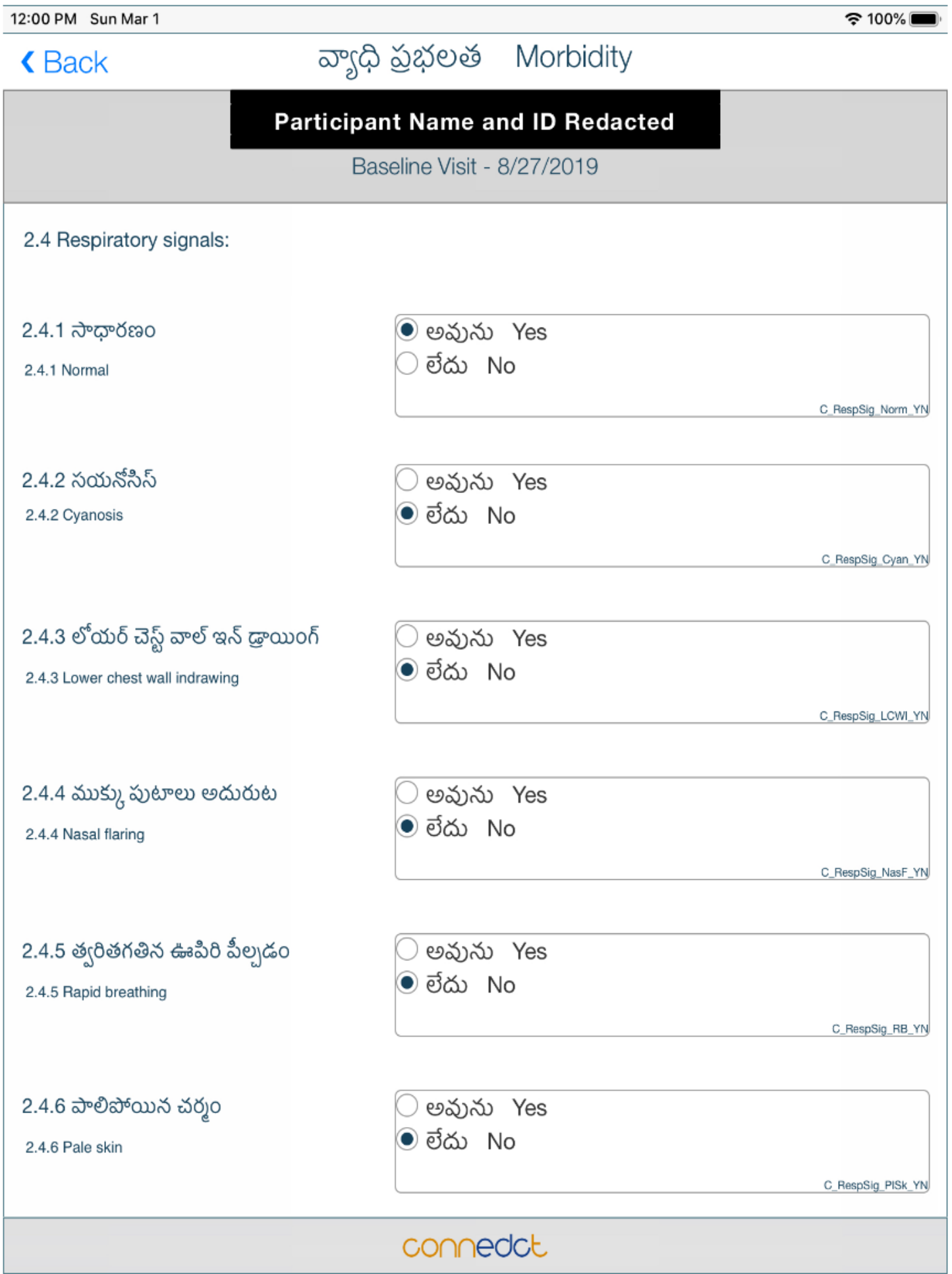

\section{Results}

\section{Description of Current Implementation: Case Studies}

The ConnEDCt platform has been used in a variety of contexts within our research teams, including cross-sectional studies in clinical settings, surveillance studies (a repeated cross-sectional study in the clinic or the community, the latter surveying thousands of households), and RCTs (Table 2). 
Table 2. ConnEDCt usage in case studies: clinic-based cross-sectional studies, surveillance studies, and randomized controlled trials.

\begin{tabular}{|c|c|c|c|c|c|}
\hline Study design & $\begin{array}{l}\text { Clinic-based cross-sec- } \\
\text { tional study }\end{array}$ & $\begin{array}{l}\text { Surveillance (repeated } \\
\text { cross-sectional studies) }\end{array}$ & $\mathrm{RCT}^{\mathrm{a}}$ & $\mathrm{RCT}$ & RCT \\
\hline Location & Ecuador & South India & Mumbai & South India & South India \\
\hline Study reference & FeverPhone & $\begin{array}{l}\text { Periconceptional pro- } \\
\text { gram }\end{array}$ & Biofortified pearl millet & $\begin{array}{l}\text { Multiple biofortified } \\
\text { food crops }\end{array}$ & $\begin{array}{l}\text { Quadruple fortified } \\
\text { salts }\end{array}$ \\
\hline ClinicalTrials.gov ID & $\mathrm{N} / \mathrm{A}^{\mathrm{b}}$ & NCT04048330 & NCT02233764 & NCT02648893 & NCT03853304 \\
\hline Status & Active & Active & Complete & Active & Planned \\
\hline $\begin{array}{l}\text { Synchronization } \\
\text { methods }\end{array}$ & $\begin{array}{l}\text { Continuously, using } \\
\text { mobile SIM card, simul- } \\
\text { taneously from multiple } \\
\text { locations }\end{array}$ & $\begin{array}{l}\text { Daily, after data collec- } \\
\text { tion }\end{array}$ & $\begin{array}{l}\text { Daily/weekly, after data } \\
\text { collection }\end{array}$ & $\begin{array}{l}\text { Daily, after data col- } \\
\text { lection }\end{array}$ & $\begin{array}{l}\text { Daily, after data collec- } \\
\text { tion }\end{array}$ \\
\hline $\begin{array}{l}\text { Number of partici- } \\
\text { pants entered into } \\
\text { ConnEDCt }\end{array}$ & $\begin{array}{l}\text { Overall } 404 \text { children } \\
\text { and adults (including } \\
\text { pregnant women) }\end{array}$ & $\begin{array}{l}2404 \text { households ( } 2876 \\
\text { women) }\end{array}$ & 407 children & $\begin{array}{l}345 \text { mother-infant } \\
\text { dyads }\end{array}$ & $\begin{array}{l}1000 \text { women of repro- } \\
\text { ductive age }\end{array}$ \\
\hline $\begin{array}{l}\text { Informed consent pro- } \\
\text { cess }\end{array}$ & $\begin{array}{l}\text { Separate consent or as- } \\
\text { sent forms depending } \\
\text { on participant's age }\end{array}$ & $\begin{array}{l}\text { Complex, depending on } \\
\text { participant's age (esti- } \\
\text { mated or actual) }\end{array}$ & $\begin{array}{l}3 \text { forms (prescreening, } \\
\text { screening, enrollment) }\end{array}$ & $\begin{array}{l}1 \text { form, with multiple } \\
\text { levels of consent }\end{array}$ & $\begin{array}{l}\text { Complex, depending on } \\
\text { participant's age (esti- } \\
\text { mated or actual) }\end{array}$ \\
\hline Eligibility & $\begin{array}{l}\text { Evaluated in real time } \\
\text { on completion of } \\
\mathrm{CRFs}^{\mathrm{c}}\end{array}$ & $\begin{array}{l}\text { Evaluated in real time } \\
\text { on completion of CRFs }\end{array}$ & $\begin{array}{l}\text { Evaluated in real time } \\
\text { on completion of CRFs }\end{array}$ & $\begin{array}{l}\text { Evaluated in real time } \\
\text { on completion of } \\
\text { CRFs }\end{array}$ & $\begin{array}{l}\text { Evaluated in real time } \\
\text { on completion of CRFs }\end{array}$ \\
\hline Unique features & $\begin{array}{l}\text { Continuous synchroniza- } \\
\text { tion across multiple lo- } \\
\text { cations simultaneously; } \\
\text { ability for forms to be } \\
\text { signed by multiple } \\
\text { study personnel to trace } \\
\text { missing information }\end{array}$ & $\begin{array}{l}\text { Only requisite CRFs } \\
\text { appear for research staff } \\
\text { to complete; complex } \\
\text { algorithm for study ID } \\
\text { creation }\end{array}$ & $\begin{array}{l}\text { Midline serial sample } \\
\text { randomization scheme }\end{array}$ & $\begin{array}{l}\text { 2-level randomization } \\
\text { to midline serial sam- } \\
\text { ple }\end{array}$ & $\begin{array}{l}\text { Only requisite CRFs } \\
\text { appear for research staff } \\
\text { to complete; randomiza- } \\
\text { tion scheme to establish } \\
2 \times 2 \text { factorial design }\end{array}$ \\
\hline Data types entered & $\begin{array}{l}\text { Laboratory assay re- } \\
\text { sults, growth measure- } \\
\text { ments, sociodemograph- } \\
\text { ic data, health history } \\
\text { and current clinical } \\
\text { signs, dietary frequen- } \\
\text { cy, and biological spec- } \\
\text { imen collection dates } \\
\text { and processing }\end{array}$ & $\begin{array}{l}\text { Laboratory assay re- } \\
\text { sults; anthropometric } \\
\text { measurements; sociode- } \\
\text { mographic data; com- } \\
\text { plete reproductive histo- } \\
\text { ry; general health histo- } \\
\text { ry and clinical signs and } \\
\text { symptoms; 24-hour re- } \\
\text { call; risk factors for } \\
\text { birth defects (environ- } \\
\text { mental exposures, med- } \\
\text { ication use, and history } \\
\text { of fever); and biological } \\
\text { specimen collection } \\
\text { volume, dates, and stor- } \\
\text { age conditions }\end{array}$ & $\begin{array}{l}\text { Laboratory assay re- } \\
\text { sults; growth measure- } \\
\text { ments, sociodemograph- } \\
\text { ic data; infant and } \\
\text { young child feeding; } \\
\text { health history and clini- } \\
\text { cal signs and symp- } \\
\text { toms; biological and } \\
\text { specimen collection } \\
\text { dates }\end{array}$ & $\begin{array}{l}\text { Laboratory assay re- } \\
\text { sults; growth measure- } \\
\text { ments, sociodemo- } \\
\text { graphic data; infant } \\
\text { and young child feed- } \\
\text { ing; health history and } \\
\text { clinical signs and } \\
\text { symptoms; and biolog- } \\
\text { ical specimen collec- } \\
\text { tion dates }\end{array}$ & $\begin{array}{l}\text { Laboratory assay re- } \\
\text { sults; anthropometric } \\
\text { measurements; sociode- } \\
\text { mographic data; com- } \\
\text { plete reproductive histo- } \\
\text { ry; general health histo- } \\
\text { ry and clinical signs and } \\
\text { symptoms; 24-hour di- } \\
\text { etary recall; food fre- } \\
\text { quency questionnaire; } \\
\text { risk factors for birth de- } \\
\text { fects (environmental } \\
\text { exposures, medication } \\
\text { use, and history of } \\
\text { fever); and biological } \\
\text { specimen collection } \\
\text { volume, dates, and stor- } \\
\text { age conditions }\end{array}$ \\
\hline $\begin{array}{l}\text { Language customiza- } \\
\text { tion }\end{array}$ & Spanish & Telugu & Hindi & Telugu & Telugu \\
\hline
\end{tabular}

${ }^{\mathrm{a}} \mathrm{RCT}$ : randomized controlled trial.

${ }^{b}$ N/A: not applicable.

${ }^{\mathrm{c}} \mathrm{CRF}$ : case report form.

\section{Clinical Research: Clinic-Based Cross-Sectional Studies}

ConnEDCt has been the primary data collection tool for clinic-based cross-sectional studies in clinical settings of Ecuador for the National Institutes of Health-funded project FeverPhone: Point of Care Diagnosis of Acute Febrile Illness using a Mobile Device and was integral in the development of the Ecuador FeverPhone project protocols and manual of operations. Multiple types of users, based at different locations, input data into separate tablet computers with distinct CRFs on participant recruitment, eligibility, and informed consent; multiple participant study visits; and specimen management and laboratory results. The integration of ConnEDCt across 
devices with daily synchronization of data to a cloud database and local computers allows research staff to easily review data for quality control, implement protocol revisions, and share progress with international collaborators.

\section{Surveillance Research: Repeated Cross-Sectional Studies in a Clinic or the Community}

The ConnEDCt platform provides the foundation for a periconceptional surveillance program, Periconceptional Surveillance for Prevention of Anemia and Birth Defects in India, funded by the US Centers for Disease Control and Prevention. This preintervention biomarker survey is being conducted among 1500 women of reproductive age (15-40 years) who are not pregnant or lactating along with their households in Southern India (ClinicalTrials.gov ID: NCT04048330; as reported in Finkelstein JL, Fothergill A, Johnson CB, et al., 2020). ConnEDCt allows enumerators to select from an imported list of households and to individually screen all women from each household while integrating all household-level data into each woman's final record. Synchronization is performed daily after data collection on all iPads. This allows for the maintenance of all household characteristics for women in the study while preventing enumerators from needing to re-enter data for all women within a household.

\section{RCTs: Intervention Studies}

The ConnEDCt platform for surveillance described above will be incorporated for an upcoming randomized efficacy trial, $A$ Randomized Trial of Quadruple Fortified Salt for Anemia and Birth Defects Prevention in Southern India (ClinicalTrials.gov ID: NCT03853304; quadruple fortified salt [QFS]). This trial will be conducted among 1000 women of reproductive age who are not pregnant or lactating with their households using similar algorithms for eligibility and CRFs for data collection as the surveillance study.

ConnEDCt was also used for an RCT in Mumbai, Effect of Iron/Zinc-biofortified Pearl Millet on Growth and Immunity in Children Aged 12-18 Months in India (ClinicalTrials.gov ID: NCT02233764) that completed data collection in July 2018 [12]. The full protocol of the study was integrated into ConnEDCt, which included the eligibility evaluation of over 400 participants; randomization to one of 2 experimental arms, accounting for a random midline serial sample; and a diverse set of CRFs to collect data from participants at 9 monthly follow-up visits. After a training session, local research assistants independently scheduled visits and collected data throughout the trial, including synchronization to the secure server. Importantly, ConnEDCt was also able to be modified after pilot testing among research assistants and participants in the field to improve the workflow, such as improving the placement of certain buttons or options on each form screen. Real-time feedback of data throughout the trial allowed for error checking concurrently with data collection. Specifically, data were exported from ConnEDCt as a relational database in the form of an Excel spreadsheet (1 per each type of CRF) using a custom script. These data were then imported and merged into 1 full database in statistical software packages and subsequently analyzed for errors, such as biologically implausible values or typographical errors during data entry. One asset of the ability to analyze the data in SAS concurrently with the trial permitted examination of the raw variables for a particular eligibility criterion necessitating advanced statistical analysis, after which results could be re-entered into ConnEDCt. The ability to access the full database concurrently as the trial was ongoing was also crucial to summarizing data, such as technical reports to the study funders and progress reports, as well as any adverse events for our data safety and monitoring board.

The EDC framework established for the Mumbai trial was customized and expanded for a second ongoing RCT evaluating multiple biofortified food crops (MBFC) in children and their mothers, Effect of a Biofortified Food Basket on Micronutrient Status and Immune and Cognitive Function among Infants in India in Madanapalle, South India (ClinicalTrials.gov ID: NCT02648893) to incorporate a different type of participant (mother-child dyads) and CRFs specific to the trial. The protocol was modified to include (1) a 2-level randomization to 1 of 4 color-coded groups, with 2 groups corresponding to each treatment arm and randomization to a midline sampling point; (2) visit scheduling and tracking over a 9-month follow-up period; and (3) data collection across integrated CRFs to handle screening and eligibility determination, sample collection, and participant tracking. A randomization protocol was created that was executed by the study statistician and shared with the ConnEDCt programmer to incorporate into the database. Similar to Mumbai, the MBFC trial is synchronizing daily after data collection during screening, baseline, and follow-up appointments.

\section{Errors During Implementation}

During implementation of data capture, the more common errors included inputting the wrong $\mathrm{CRF}$ for a participant at the wrong visit or miscoding variables (eg, a numeric coding for a character variable). These were easily resolved by the database developer and/or data manager.

\section{Discussion}

\section{Principal Findings}

The benefits of using ConnEDCt as an EDC system greatly outweigh the few challenges. Below, we describe how we addressed potential or actual issues of connectivity, complexity in consent forms, participant confidentiality, and research staff compliance.

\section{Problem 1: Connectivity}

In all settings, data were synchronized to the server and the participant's data were harmonized by the MirrorSync software [5]. To account for lapses in internet connectivity and prevent data conflicts, synchronization was performed at the end of each day of data collection in the RCTs to avoid data conflicts and any need for internet connectivity throughout the data collection process. In practice, $1 \mathrm{iPad}$ was assigned to a particular participant for the duration of the visit and, after completion of the visit, all iPads were synced to the data server.

In contrast to RCTs, the clinic-based cross-sectional study in Ecuador (FeverPhone) required multiple users to input data for 
a single participant using separate devices in different clinical locations. Therefore, regular synchronization was important for study procedures. The clinical site did not offer wireless internet access, but each iPad was fitted with a prepaid mobile SIM card to allow for regular synchronization during participant visits.

For the periconceptional surveillance program, the database was designed such that iPads could remain at 1 station for data collection while participants moved from station to station. This greatly simplified data collection and allowed each enumerator to continue using the same iPad to help track enumerator productivity and workflow.

\section{Problem 2: Complex Consent Forms}

In Mumbai's RCT, informed consent was taken at 3 separate visits: prescreening (consent to noninvasive data collection), screening (consent to biospecimen collection and growth measurements), and enrollment (consent to participate in the trial), including informed consent signatures per the type of data collected. During follow-up, we included informed consent signatures on biological specimen collection forms to remind participants of their option to opt out of the trial at any time.

One RCT in Southern India, the MBFC trial, combined the informed consent process into a single form, with multiple levels of consent. Participants were asked separately for their consent to screening and participation in the trial, subsequent biological sample storage and analysis, and future analyses of their biological samples, which may include genetic analysis. This allowed documentation and tracking of different levels of consent for each participant as well as allowing for tracking of which participants consented to future analyses.

At the Ecuador clinical site, study procedures required separate consent or assent forms depending on the participant's age. ConnEDCt automatically provided the appropriate consent or assent forms based on the date of birth information provided in the recruitment CRF. ConnEDCt would further limit progress to subsequent CRFs if the appropriate consent or assent forms were incomplete.

The periconceptional surveillance study in Southern India has a complex informed consent process because of multiple factors influencing eligibility and additional factors to determine which set of informed consent forms need to be completed. In the periconceptional surveillance program, participants included adolescents aged 15 to 18 years (requiring an assent form and parental consent) and adults ( $\geq 18$ years of age, requiring a consent form) are potentially eligible to participate. To ensure that participants complete the correct forms and that all required signatures are obtained, the participant's age (to the day) is required in real time. ConnEDCt was able to be adapted for this purpose to determine a participant's eligibility, and which set of forms they needed to complete to enroll. Additionally, to account for variable amounts of information being available for the determination of current age, we developed an algorithm that considered all available information (current age, exact date of birth, and estimated/partial date of birth). The database developer built the algorithm into ConnEDCt such that research assistants entered data available to them, and the software made visible the CRFs that they needed to proceed (eg, CRFs indicating the participant was eligible and which set of assent/consent forms they needed to sign). To simplify and streamline the process, we adapted ConnEDCt such that it only allowed necessary CRFs to appear on the iPad for the research assistants, making it impossible for research assistants to fill out the incorrect set of CRFs.

\section{Problem 3: Confidentiality}

Confidentiality was maintained in RCTs, clinic-based cross-sectional studies, and repeated cross-sectional studies, such as our surveillance program, through many layers of security. First, each field personnel had their own computer-generated unique username and password to access the database. Second, although participant names were included in the database to facilitate tracking of each participant locally, names were easily removed for deidentification after exporting the data. Participants were identified with ID numbers derived from a 4-digit sequentially generated code and a letter corresponding to the participant's color group study allocation.

The periconceptional surveillance program includes women of reproductive age and their families-and a hierarchical data structure. In the database, each participant has an identifying individual participant ID and a household ID, which in combination, uniquely identifies them as a participant in the periconceptional surveillance program; the latter being generated by ConnEDCt. Their personal ID incorporates a code that indicates that they are a participant in the surveillance program, a code indicating which iPad their data were collected on, and an additional 4-digit code (generated sequentially by ConnEDCt) to ensure that all participants have unique IDs. This identification system in ConnEDCt allows for an undetermined number of participants to be enrolled in the surveillance program while ensuring that no duplicate IDs are utilized. The structure of the IDs ( 3 concatenated codes) also provides flexibility to add and remove pieces to indicate the person's participation in potential future studies led by the Finkelstein research group in this area (eg, for the upcoming QFS randomized efficacy trial).

\section{Problem 4: Compliance}

The data collected in the periconceptional surveillance program are very detailed and complex. To improve data quality during collection, we built various safeguards into the data collection tools. For free-entry numeric variables, limits were placed around values entered that would flag responses and indicate enumerators that data entered seemed implausible. For example, if a participant's weight was entered as $1 \mathrm{~kg}$, a flag would pop up on the iPad screen, indicating that the response was outside the anticipated range and ask the enumerator to verify the entry before moving forward. In addition to raw variable entry, these flags were also built in to read across multiple variables that were deemed to be of high importance. If a participant's response was left blank, or if a response to question 1 directly contradicted with an entry for question 3 , a flag would pop up and ask the enumerator to verify before continuing. Finally, various time stamps were built into variables throughout the questionnaire to allow for remote monitoring of enumerator progress. Enumerators had to log in using their unique username and password before any data entry and had to sign each form 
they entered data on using their unique username and password before they could continue.

The RCTs incorporated similar compliance measures into the ConnEDCt EDC system, including real-time calculations for replicate measurements, thresholds for variation to prompt additional replicates, and flagging of responses outside of expected ranges. Adaptive and forced protocols are also implemented into CRFs. For example, anthropometric measurements for the first replicate need to be entered before the next replicate fields will be displayed, meaning a full replicate of the measurement protocol is followed instead of basic remeasurements with participants and equipment in the same position. Adaptive protocols and instructions are also included. For example, for certain anthropometric measurements such as triceps skinfold, the research assistant determines the participant's dominant arm, triggering ConnEDCt to prompt the research assistant to use the participant's other, nondominant arm. Furthermore, warning pop-ups (logic checks) for impossible or nonbiologically plausible data (such as body weight entered or calculated as a negative number) were incorporated into ConnEDCt, allowing real-time data correction during data collection, minimizing challenges in ascertaining errors during data cleaning and analysis. Queries, raised by research assistants and/or data managers concurrently with the study or after data collection is completed, can be settled by data managers who have form modification privileges. ConnEDCt includes an audit trail to monitor when data were modified and by whom.

\section{Conclusions}

ConnEDCt, an EDC system, is an ideal tool for research studies, particularly those with complex protocols in settings where internet access is limited. In addition to mitigating the time required and error-prone nature of paper-based data collection methods, ConnEDCt represents a fixed framework that is adaptable to a variety of study designs. As demonstrated in a variety of settings, the ConnEDCt EDC system has been integral to carrying out several studies, all diverse in design and setting, types of participants, and overall goals for the research. Compared with other EDC tools [1,2,13-24], ConnEDCt's benefits, including its utility as a mobile system, the ability to collect data without internet access, customization options for specific study designs, and data security, are comparable with systems such as REDCap and other systems [3,25,26], while at the same time serving complex protocols more precisely than other systems. An EDC system can be made as a straightforward framework that is adaptable for the successful management and completion of almost all kinds of field-based research studies and allows for easy export and transfer of collected data into statistical processing software for further analyses.

\section{Acknowledgments}

The authors gratefully acknowledge Guanglan Zhang, Associate Professor of Computer Science at Boston University, who provided guidance and advice; Elaine $\mathrm{A} Y \mathrm{Yu}, \mathrm{PhD}$ from Cornell University, who designed the forms and piloted the initial ConnEDCt design in South India; Françoise Vermeylen from Cornell University for her expertise in generating the randomization list for our studies; our intern study coordinators from our RCTs in Mumbai, Laura Powis and Yadurshini Raveendran for field testing and troubleshooting; and, finally, all patients, participants, and research assistants and community health workers from our studies in Mumbai, South India, and Ecuador. SM and JF acknowledge support from HarvestPlus and the National Institute of Biomedical Imaging and Bioengineering of the National Institutes of Health under Award Number R01EB021331 for the research studies in which ConnEDCt was initially implemented. AF and CJ were supported by the National Institutes of Health under award 5 T32 HD087137. The content in this paper is solely the responsibility of the authors and does not necessarily represent the official views of National Institute of Biomedical Imaging and Bioengineering, the Eunice Kennedy Shriver National Institute of Child Health and Human Development or the National Institutes of Health. The publication costs of this manuscript were supported by the Bill and Melinda Gates Foundation through their open access fund.

\section{Conflicts of Interest}

SM is an unpaid board member for a diagnostic start-up focused on developing point-of-care assays for nutritional status informed by his research as a faculty member at Cornell University. CR is the owner of Data Performance LLC, which owns the trademark and commercial rights to the ConnEDCt software. All other authors have no competing interests to declare.

\section{References}

1. Walther B, Hossin S, Townend J, Abernethy N, Parker D, Jeffries D. Comparison of electronic data capture (EDC) with the standard data capture method for clinical trial data. PLoS One 2011;6(9):e25348 [FREE Full text] [doi: 10.1371/journal.pone.0025348] [Medline: 21966505]

2. Malik I, Burnett S, Webster-Smith M, Morden J, Ereira S, Gillman A, et al. Benefits and challenges of electronic data capture (EDC) systems versus paper case report forms. Trials 2015 Nov 16;16(S2):-. [doi: 10.1186/1745-6215-16-s2-p37]

3. Harris PA, Taylor R, Minor BL, Elliott V, Fernandez M, O'Neal L, REDCap Consortium. The REDCap consortium: building an international community of software platform partners. J Biomed Inform 2019 Jul;95:103208. [doi: 10.1016/j.jbi.2019.103208] [Medline: 31078660]

4. Hartung C, Lerer A, Anokwa Y, Tseng C, Brunette W, Borriello G. Open Data Kit: Tools to Build Information Services for Developing Regions. In: Proceedings of the 4th ACM/IEEE International Conference on Information and Communication 
Technologies and Development. 2010 Presented at: ICTD'10; December 13-16, 2010; London, United Kingdom. [doi: $10.1145 / 2369220.2369236]$

5. 360Works MirrorSync: FileMaker Sync for FileMaker Server, FileMaker Pro, and FileMaker Go on iPhone and iPad, FileMaker offline sync. URL: https://www.360works.com/filemaker-sync.html [accessed 2020-06-30]

6. Ruth C, Yu E, Huey S, Chitkushev L, Mehta S, Zhang G. ConnEDCt: A Development Framework for Mobile Electronic Data Capture in Disconnected Communities. In: 12th Annual International Conference on Computer Science and Education in Computer Science. 2016 Presented at: SIGCSE'16; July 1-4, 2016; Nürnberg, Germany URL: https://csecs.org/ conference-schedule-2/

7. Claris FileMaker-tackle any task. URL: https://www.claris.com/filemaker/ [accessed 2020-07-15]

8. Cornu C, Donche A, Coffre C, le Gouge A, Rym B, Vaugier I, Comité de pilotage du groupe de travail harmonisation des procédures de réseau des CIC. [ECRIN standard requirements for good clinical practices-compliant data management in multinational clinical trials]. Therapie 2016 Oct 13:- epub ahead of print. [doi: 10.2515/therapie/2015042] [Medline: 27839710]

9. Computerized Systems Used in Clinical Investigations. US Food and Drug Administration. 2007. URL: https://www. fda.gov/regulatory-information/search-fda-guidance-documents/computerized-systems-used-clinical-investigations [accessed 2020-06-26]

10. Bansal A, Chamberlain R, Karr S, Kwasa S, McLaughlin B, Nguyen B, et al. A 21 CFR part 11 compliant graphically based electronic system for clinical research documentation. J Med Syst 2012 Jun;36(3):1661-1672. [doi: 10.1007/s10916-010-9627-4] [Medline: 21107888]

11. CFR - Code of Federal Regulations Title 21. US Food and Drug Administration. URL: https://www.accessdata.fda.gov/ scripts/cdrh/cfdocs/cfcfr/cfrsearch.cfm [accessed 2020-06-26]

12. Mehta S, Finkelstein JL, Venkatramanan S, Huey SL, Udipi SA, Ghugre P, et al. Effect of iron and zinc-biofortified pearl millet consumption on growth and immune competence in children aged 12-18 months in India: study protocol for a randomised controlled trial. BMJ Open 2017 Nov 14;7(11):e017631 [FREE Full text] [doi: 10.1136/bmjopen-2017-017631] [Medline: 29138201]

13. Aroda VR, Sheehan PR, Vickery EM, Staten MA, LeBlanc ES, Phillips LS, D2d Research Group. Establishing an electronic health record-supported approach for outreach to and recruitment of persons at high risk of type 2 diabetes in clinical trials: the vitamin D and type 2 diabetes (D2d) study experience. Clin Trials 2019 Jun;16(3):306-315 [FREE Full text] [doi: 10.1177/1740774519839062] [Medline: 31007049]

14. Barton J, Young A, Lay M. Introduction of electronic data capture method using participant-completed online web-based follow up questionnaire in mail-based study achieves expected benefits and positive participant feedback. Trials 2015 Nov 16;16(S2):-. [doi: 10.1186/1745-6215-16-s2-p44]

15. Bingham CO, Gaich CL, DeLozier AM, Engstrom KD, Naegeli AN, de Bono S, et al. Use of daily electronic patient-reported outcome (PRO) diaries in randomized controlled trials for rheumatoid arthritis: rationale and implementation. Trials 2019 Mar 22;20(1):182 [FREE Full text] [doi: 10.1186/s13063-019-3272-0] [Medline: 30902094]

16. Drew CJ, Poile V, Trubey R, Watson G, Kelson M, Townson J, et al. Integrating technology into complex intervention trial processes: a case study. Trials 2016 Nov 17;17(1):551 [FREE Full text] [doi: 10.1186/s13063-016-1674-9] [Medline: 27855710]

17. Ene-Iordache B, Carminati S, Antiga L, Rubis N, Ruggenenti P, Remuzzi G, et al. Developing regulatory-compliant electronic case report forms for clinical trials: experience with the demand trial. J Am Med Inform Assoc 2009;16(3):404-408 [FREE Full text] [doi: 10.1197/jamia.M2787] [Medline: 19261946]

18. Haynes R. Minimising paper: electronic data capture methods in the 3c study. Trials 2013 Nov 29;14(S1):-. [doi: 10.1186/1745-6215-14-s1-p60]

19. Hutton D, Smith N, Cappel-Porter H, Saw C, Rogers C. Development of the 'GeneSYS' database system to support trial data capture and conduct. Trials 2013;14(Suppl 1):P66. [doi: 10.1186/1745-6215-14-s1-p66]

20. Lewis R, Batten L, Friend C, Webster-Smith M, Burnett S, Morden J, et al. Design considerations when transitioning from paper case report forms (CRFS) to electronic data capture (EDC). Trials 2015 Nov 16;16(S2):-. [doi: $10.1186 / 1745-6215-16-s 2-p 35]$

21. Seebregts CJ, Zwarenstein M, Mathews C, Fairall L, Flisher AJ, Seebregts C, et al. Handheld computers for survey and trial data collection in resource-poor settings: development and evaluation of PDACT, a palm pilot interviewing system. Int J Med Inform 2009 Nov;78(11):721-731. [doi: 10.1016/j.ijmedinf.2008.10.006] [Medline: 19157967]

22. Webster-Smith M, Paulding C, Burnett S, Jeffs L, Ismail D, McNamara C, et al. Implementing electronic data capture (EDC) training for site staff. Trials 2015 Nov 16;16(S2):-. [doi: 10.1186/1745-6215-16-s2-p41]

23. Yu P, de Courten M, Pan E, Galea G, Pryor J. The development and evaluation of a PDA-based method for public health surveillance data collection in developing countries. Int J Med Inform 2009 Aug;78(8):532-542. [doi:

10.1016/j.ijmedinf.2009.03.002] [Medline: 19369114]

24. Zhang J, Sun L, Liu Y, Wang H, Sun N, Zhang P. Mobile device-based electronic data capture system used in a clinical randomized controlled trial: advantages and challenges. J Med Internet Res 2017 Mar 8;19(3):e66 [FREE Full text] [doi: 10.2196/jmir.6978] [Medline: 28274907] 
25. Harris PA, Taylor R, Thielke R, Payne J, Gonzalez N, Conde JG. Research electronic data capture (REDCap)--a metadata-driven methodology and workflow process for providing translational research informatics support. J Biomed Inform 2009 Apr;42(2):377-381 [FREE Full text] [doi: 10.1016/j.jbi.2008.08.010] [Medline: 18929686]

26. Elliot R, Sawkar M, Williams M. The Power of Mobile Platorms for Data Collecion. The Agriculture, Nutrition \& Health (ANH) Academy. 2019. URL: https://www.anh-academy.org/sites/default/files/ SightandLifeMagazine 2019 Data in Nutrition ThePowerofMobilePlatformsforDataCollection 0.pdf [accessed 2020-06-26]

\section{Abbreviations}

CFR: Code of Federal Regulations

CRF: case report form

EDC: electronic data capture

FDA: Food and Drug Administration

MBFC: multiple biofortified food crops

QFS: quadruple fortified salt

RCT: randomized controlled trial

REDCap: Research Electronic Data Capture

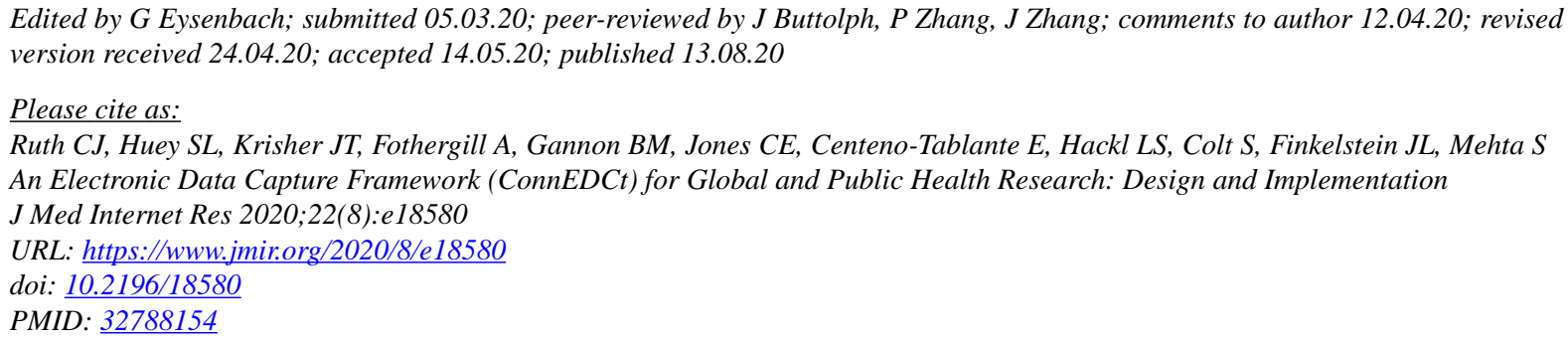

(C)Caleb J Ruth, Samantha Lee Huey, Jesse T Krisher, Amy Fothergill, Bryan M Gannon, Camille Elyse Jones, Elizabeth Centeno-Tablante, Laura S Hackl, Susannah Colt, Julia Leigh Finkelstein, Saurabh Mehta. Originally published in the Journal of Medical Internet Research (http://www.jmir.org), 13.08.2020. This is an open-access article distributed under the terms of the Creative Commons Attribution License (https://creativecommons.org/licenses/by/4.0/), which permits unrestricted use, distribution, and reproduction in any medium, provided the original work, first published in the Journal of Medical Internet Research, is properly cited. The complete bibliographic information, a link to the original publication on http://www.jmir.org/, as well as this copyright and license information must be included. 